Dieses Dokument ist eine Zweitveröffentlichung (Postprint Version) / This is a self-archiving document (accepted version):

Dmitriy I. Shiman, Vladimir Sayevich, Christian Meerbach, Pavel A. Nikishau, Irina V. Vasilenko, Nikolai Gaponik, Sergei V. Kostjuk, Vladimir Lesnyak

Robust Polymer Matrix Based on Isobutylene (Co)polymers for Efficient Encapsulation of Colloidal Semiconductor Nanocrystals

Erstveröffentlichung in / First published in:

ACS Applied Nano Materials. 2019, 2 (2), S. 956 - 963. ACS Publications. ISSN: 2574-0970.

DOI: https://doi.org/10.1021/acsanm.8bo2262

Diese Version ist verfügbar / This version is available on:

https://nbn-resolving.org/urn:nbn:de:bsz:14-qucosa2-743220 


\title{
Robust Polymer Matrix Based on Isobutylene (Co)Polymers for Efficient Encapsulation of Colloidal Semiconductor Nanocrystals
}

\author{
Dmitriy I. Shiman, ${ }^{1,2}$ Vladimir Sayevich, ${ }^{1}$ Christian Meerbach, ${ }^{1}$ Pavel A. Nikishau, ${ }^{2}$ Irina V. \\ Vasilenko, ${ }^{2}$ Nikolai Gaponik, ${ }^{1}$ Sergei V. Kostjuk, ${ }^{2,3,4}$ Vladimir Lesnyak ${ }^{1 *}$
}

${ }^{1}$ Physical Chemistry and Center for Advancing Electronics Dresden (cfAED), TU Dresden, Bergstr. 66b, 01062 Dresden, Germany

${ }^{2}$ Research Institute for Physical Chemical Problems of the Belarusian State University, Leningradskaya Str. 14, 220030 Minsk, Belarus

${ }^{3}$ Sechenov First Moscow State Medical University, Institute for Regenerative Medicine, 119991 Moscow, Russia

${ }^{4}$ Department of Chemistry, Belarusian State University, Leningradskaya Str. 14, 220006 Minsk, Belarus

E-mail: vladimir.lesnyak@chemie.tu-dresden.de

\begin{abstract}
We introduce new oxygen- and moisture-proof polymer matrices based on polyisobutylene (PIB) and its block copolymer with styrene PIB-b-PSt for encapsulation of colloidal semiconductor nanocrystals. In order to prepare transparent and processable composites, we developed a special procedure of the nanocrystal surface engineering including ligand exchange of parental organic ligands to inorganic species followed by attachment of specially designed shortchain PIB functionalized with amino-group (PIB-NH 2$)$. The latter provides excellent compatibility of the particles with the polymer matrices. As colloidal nanocrystals we chose CdSe nanoplatelets (NPLs), since they possess a large surface and thus are very sensitive to the environment, in particular in terms of their limited photostability. The encapsulation strategy is quite general and can be applied
\end{abstract}


to a wide variety of semiconductor nanocrystals, as demonstrated on the example of $\mathrm{PbS}$ quantum dots. All obtained composites exhibited excellent photostability being tested in a focus of a powerful white-light source, as well as exceptional chemical stability in a strongly acidic media. We compared these properties of the new composites with those of widely used polyacrylate based materials, demonstrating the superiority of the former. The developed composites are of particular interest for application in optoelectronic devices, such as color-conversion light emitting diodes (LEDs), laser diodes, luminescent solar concentrators, etc.

\section{INTRODUCTION}

Colloidal semiconductor nanocrystals (also known as quantum dots (QDs)), represented mainly by metal chalcogenide compounds, have been one of the most studied materials due to their unique quantum confinement effects and size dependent optoelectronic characteristics. ${ }^{1-2}$ QDs exhibit desirable optical features, such as widely tuneable absorption spectra extending over a broad wavelength range, high photoluminescence (PL) efficiency, narrow emission spectral bandwidths, and the possibility to tune optical spectra by varying their size, shape, and composition. These highly fluorescent nanocrystals have shown great potential in thin film light-emitting diodes (LEDs), ${ }^{3-4}$ solar cells, ${ }^{5-6}$ solar concentrators, ${ }^{7-8}$ photodetectors, and as biological labels ${ }^{9-10}$. The highest quality QDs, especially in terms of their optical properties, achieved so far are synthesized by so-called hotinjection approach in high boiling organic solvents. These nanoparticles bare on their surface organic ligands typically containing a polar group anchored to the QD and nonpolar hydrocarbon tail imparting QDs solubility in organic solvents. ${ }^{11}$

One of the main problems in technological processing and practical applications of QDs and thus their commercialization is an insufficient stability of the materials upon working device conditions (e.g. at elevated temperatures, applied electrical current, high-power photoexcitation, etc.) against oxidation and humidity leading to poor long-term durability of QD-based materials and devices. For example, atmospheric oxygen can react with unprotected QDs' surface forming complex 
oxidized species (either with metal or with chalcogen), which eventually results in drastic deterioration of their unique optical and electronic properties, such as conductivity, mobility, carrier relaxation dynamics, and PL quantum yield (QY). The latter is the most important characteristic for application of QDs in LEDs. In order to prevent the degradation of the QD surface, usually they are encapsulated into stable matrices, such as polymers, ${ }^{12-14}$ silica, ${ }^{15-16}$ inorganic salts, ${ }^{17-21}$ and metal oxides $^{22}$. Among them, polymer matrices are typically based on polyacrylates ${ }^{13,23-24}$ and polystyrene ${ }^{12,14}$. However, most of these polymers still exhibit remarkable permeability for gases, especially for oxygen. Additionally, many available polymerization methods cannot provide high QD loading into polymer matrices due to their phase separation and aggregation. Therefore, the development of appropriate gas-proof polymer matrices with high QD concentration is of paramount importance for successful practical application of QDs.

We currently turn our attention to a development of functional short-chain capping ligands in which strong binding affinity to the QD surface and passivation properties are supplemented by easyto-integrate capabilities into long-chain polymer host matrices. These functionalized QDs can be dispersed in the polymer matrix via hydrophobic interactions between QD's surface molecules and polymer backbones enabling precise control over QD-to-polymer ratios and optical properties of the composite material. This new strategy is different from other methods of QD-functionalization, including the attachment of the polymer molecules directly to the QD surface by multiple ${ }^{25}$ or single bonds, ${ }^{26}$ or polymerization of monomer molecules directly from or on QD surface ${ }^{12,27-28}$. Thus, our group recently demonstrated that amine-based functional ligands can readily replace the positively charged diffusion region around the all-inorganic-capped QDs regardless of their complex structure, composition, morphology and surface chemistry. ${ }^{29-31}$ This led to successful surface modification of the QDs with biocompatible and thermally decomposing ligands for biomedical and electronic applications, respectively. ${ }^{29,31}$

In this work, we report the design and the synthesis of oligoisobutylene ligand containing amino-functional anchoring groups (PIB- $\mathrm{NH}_{2}$ ), subsequent surface modification of colloidal QDs 
with these molecules and finally, fabrication of nanocrystals-in-polymer thin film composites via incorporation of the PIB-NH2-funtionalized QDs. As guest nanocrystals, we chose CdSe nanoplatelets (NPLs) and quasi-spherical PbS QDs due to their widely reported high sensitivity to environmental conditions. ${ }^{32-33} \mathrm{We}$ particularly focused on the fluorescence properties of these nanocrystals, since they are a direct indication of changes occurring on the surface, such as oxidation, which typically leads to PL quenching due to the formation of surface trap states. As a polymer matrix, we selected polyisobutylene (PIB), one of the polymer materials with known exceptionally low gas permeability ${ }^{34}$. In addition, PIB exhibits such unique properties, as a significant thermal and chemical stability, one of the weakest temperature dependences of structural relaxation and viscosity (i.e., low fragility), and an excellent flexibility at ambient temperatures. ${ }^{35}$ Thus, Faust et al. recently showed that the PIB-based polymers possess excellent barrier properties, in particular oxygen permeability of only $1.9 \times 10^{-16} \mathrm{~mol} \cdot \mathrm{m} \cdot \mathrm{m}^{-2} \cdot \mathrm{s}^{-1} \cdot \mathrm{Pa}^{-1}$ and moisture permeability of $46 \cdot 10^{-16} \mathrm{~mol} \cdot \mathrm{m} \cdot \mathrm{m}^{-}$ ${ }^{2} \cdot \mathrm{s}^{-1} \cdot \mathrm{Pa}^{-1}$, which were highly beneficial for encapsulation of flexible organics solar cells. ${ }^{36-37}$ All these characteristics make PIB a perfect candidate for efficient encapsulation of various semiconductor nanocrystals. In addition to pure PIB, we also synthesized a block copolymer of isobutylene with styrene (PIB-b-PSt) and studied these two polymers as host matrices to prepare nanoparticles-inpolymer solid composites in the form of thin films deposited on glass slides. To compatibilize the NPLs with polymers we developed a special surface engineering approach consisting in anchoring PIB-containing ligands to the surface of the particles. In this way, original organic ligands were first replaced by sulfide or iodide ions forming all-inorganic nanocrystals, followed by attaching $\mathrm{PIB}-\mathrm{NH}_{2}$ moieties. These surface functionalized nanoparticles formed transparent composites with both polymers, which exhibited an excellent stability against photodegradation as well as in strongly acidic media. In order to demonstrate advantages of these new matrices we compared the composites with NPLs-in-poly(lauryl methacrylate) (PLMA), a commonly used polymer to encapsulate QDs. Indeed, both NPLs-in-PIB and NPLs-in- PIB-b-PSt showed superior stability, that makes them perspective materials for application as color-conversion layers in LEDs and laser diodes. 


\section{EXPERIMENTAL SECTION}

Complexes of $\mathbf{A l C l}_{3}$ with ${ }^{t} \mathbf{B u O M e}$ (as $1 \mathrm{M}$ solution in $\mathrm{CH}_{2} \mathrm{Cl}_{2}$ ) were synthesized following the recipe described in ref. ${ }^{38}$.

Synthesis of 6-phenoxyhexan-1-amine was carried out according to the described method. ${ }^{39}$ Details of the synthesis are provided in the Supporting Information.

Dicumyl chloride was synthesized according to the method described in ref. ${ }^{40}$ via passing gaseous $\mathrm{HCl}$ through a solution of 1,4-bis(2-hydroxyisopropyl)benzene in methylene chloride at $0{ }^{\circ} \mathrm{C}$. Then the product of synthesis was twice recrystallized from $n$-hexane and dried in vacuum.

All polymerization reactions were carried out in glass tubes under argon at different temperatures.

Synthesis of low molecular weight chlorine-terminated polyisobutylene following the recipe from ref. ${ }^{38}$. Briefly, the solution of $\mathrm{AlCl}_{3} \cdot{ }^{t} \mathrm{BuOMe}$ in $\mathrm{CH}_{2} \mathrm{Cl}_{2}(0.6 \mathrm{~mL}, 1 \mathrm{M})$ was added to a mixture of $1.43 \mathrm{~g}$ isobutylene $(25.5 \mathrm{mmol})$ and $25 \mathrm{~mL}$ toluene at $-20^{\circ} \mathrm{C}$. After 10 minutes, the reaction mixture was poured into ethanol. The resulting precipitate of PIB was dissolved in $20 \mathrm{~mL} n$-hexane., washed with $0.5 \mathrm{M}$ nitric acid and deionized water to remove the aluminum-containing residues, evaporated to dryness under reduced pressure, and dried in vacuum at $60{ }^{\circ} \mathrm{C}$ to give the product polymers.

Synthesis of high molecular weight polyisobutylene. $0.3 \mathrm{~mL}$ of $\mathrm{TiCl}_{4}$ was added to a mixture of $2.03 \mathrm{~g}$ isobutylene (26.3 mmol), $18.8 \mathrm{~mL} n$-hexane, $14.4 \mathrm{~mL} \mathrm{CH}_{2} \mathrm{Cl}_{2}$ ), the solution of 2,6-di-tertbutylpyridine $(1.65 \mathrm{ml}, 0.1 \mathrm{M})$ in $n$-hexane, and $0.3 \mathrm{~mL}$ dicumyl chloride at $-80{ }^{\circ} \mathrm{C}$. After 2 hours, the reaction mixture was poured into methanol. The resulting precipitate of PIB was dissolved in $20 \mathrm{~mL}$ $n$-hexane. Then the solution was centrifuged at $10000 \mathrm{rpm}$ for $10 \mathrm{~min}$ to remove insoluble products of alcoholysis of $\mathrm{TiCl}_{4}$. Clear supernatant was mixed with $100 \mathrm{~mL}$ of methanol resulting in flocculation of PIB with its subsequent drying in vacuum.

Synthesis of poly(styrene-block-isobutylene-block-styrene) was carried out according to the described method, ${ }^{40}$ by using pyridine instead of 2,6-di-tret-butylpyridine. Briefly, $0.2 \mathrm{~mL}$ of $\mathrm{TiCl}_{4}$ was added to a mixture of $1.35 \mathrm{~g}$ isobutylene $(24.1 \mathrm{mmol}), 12.6 \mathrm{~mL} n$-hexane, $9.6 \mathrm{~mL} \mathrm{CH}_{2} \mathrm{Cl}_{2}, 1.1$ 
$\mathrm{mL}$ of the solution of pyridine in $n$-hexane $(0.1 \mathrm{M})$, and the solution of $0.7 \mathrm{~mL}$ dicumyl chloride (synthesized as described above) in $n$-hexane $(0.1 \mathrm{M})$ at $-80^{\circ} \mathrm{C}$. After $35 \mathrm{~min}, 3.5 \mathrm{~mL}$ of styrene solution in mixture of $n$-hexane $/ \mathrm{CH}_{2} \mathrm{Cl}_{2}(60 / 40 \mathrm{v} / \mathrm{v})$ cooled to $-30{ }^{\circ} \mathrm{C}$ were added to the mixture. The reaction was quenched by pouring the mixture into methanol after $30 \mathrm{~min}$. Thus obtained copolymer was purified similar to the high molecular weight PIB.

Synthesis of poly(lauryl methacrylate). $9.5 \mathrm{~mL}$ freshly distilled lauryl methacrylate (32 mmol) were polymerized in the presence of $41 \mathrm{mg} \operatorname{AIBN}(0.25 \mathrm{mmol})$ at $60^{\circ} \mathrm{C}$ for $48 \mathrm{~h}$.

4-(6-aminohexoxy)phenyl-polyisobutylene $\left(\mathrm{PIB}-\mathrm{NH}_{2}\right)$ was synthesized via Friedel-Crafts alkylation of 6-phenoxyhexan-1-amine $\left(\mathrm{RNH}_{2}\right)$ (details of the synthesis are in the Supporting Information) by chlorine-terminated PIB with $\mathrm{M}_{\mathrm{n}}=1 \times 10^{3}$ in glass tubes under argon at $-70{ }^{\circ} \mathrm{C} .{ }^{39}$ The

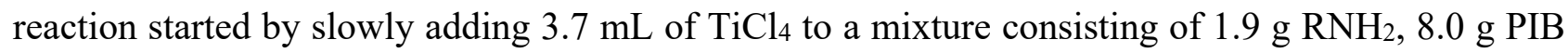
(8 mmol), $60 \mathrm{~mL} \mathrm{CH}_{2} \mathrm{Cl}_{2}$, and $40 \mathrm{~mL} n$-hexane. Reaction proceeded during $9 \mathrm{~h}$, after that the catalyst was decomposed by adding $\sim 5 \mathrm{~mL}$ ethanol, followed by dilution of the reaction mixture with $60 \mathrm{~mL}$ $n$-hexane. The obtained solution was repeatedly washed with water until the aqueous layer remained colorless. The organic layer was collected and repeatedly washed with $3 \%$ aqueous $\mathrm{KOH}$ solution until the $\mathrm{pH}$ value of organic layer reached 6-7. The organic layer was separated and washed with water:ethanol $(90: 10 \mathrm{v} / \mathrm{v})$ mixture, followed by drying with anhydrous magnesium sulfate with subsequent and filtering. Then the solvent was removed and the polymer was dried in vacuum.

Synthesis of 4 ML CdSe NPLs. A mixture of $70 \mathrm{mg} \mathrm{CdO}(0.54 \mathrm{mmol})$ and $340 \mathrm{mg}$ myristic acid $(1.4 \mathrm{mmol})$ in $28 \mathrm{~mL}$ ODE was degassed at $110^{\circ} \mathrm{C}$ for $30 \mathrm{~min}$ in a $50-\mathrm{mL}$ three-neck flask. The resulting reddish precursor solution was heated up to $285^{\circ} \mathrm{C}$ under argon atmosphere. After 20 min the solution became completely transparent and was degassed again at $90^{\circ} \mathrm{C}$ before adding $24 \mathrm{mg} \mathrm{Se}$ powder $(0.3 \mathrm{mmol})$ suspended in $2 \mathrm{~mL}$ ODE. Thereafter, the reaction mixture was heated up to $240^{\circ} \mathrm{C}$ with swift addition of $160 \mathrm{mg} \mathrm{Cd}(\mathrm{OAc})_{2} \cdot 2 \mathrm{H}_{2} \mathrm{O}(0.64 \mathrm{mmol})$ at $190-200^{\circ} \mathrm{C}$. After $10 \mathrm{~min}$ at $240^{\circ} \mathrm{C}$ the reaction was quenched by rapid cooling with a water bath and the addition of $1 \mathrm{~mL} \mathrm{OlAc}$ at $180^{\circ} \mathrm{C}$. The solution was divided into two parts and placed in $50 \mathrm{~mL}$ centrifugation tubes; $20 \mathrm{~mL}$ of a $n$ - 
hexane:ethanol $(3: 1 \mathrm{v} / \mathrm{v})$ mixture were added to each portion with subsequent centrifugation at $4000 \mathrm{rpm}(\mathrm{rcf}=1972 \mathrm{~g})$ for $10 \mathrm{~min}$. The precipitate was dissolved in $4 \mathrm{~mL}$ of $n$-hexane.

Synthesis of PbS QDs. Quasi-spherical PbS QDs with an average size of $3.3 \mathrm{~nm}$ and a narrow size distribution were synthesized using a modified literature procedure by Hines et al. $^{41}$ In a typical reaction, a mixture of $223.2 \mathrm{mg} \mathrm{PbO}, 20 \mathrm{~mL}$ ODE, $1.27 \mathrm{~mL}$ OlAc, and $1 \mathrm{~mL}$ TOP in a $50 \mathrm{~mL}$ threeneck flask was heated up to $105^{\circ} \mathrm{C}$ and kept under vacuum $\left(\sim 10^{-2}\right.$ mbar $)$ for 2 hrs. Thereafter, the flask was filled with argon and the temperature was raised to $150^{\circ} \mathrm{C}$ until a clear solution formed. Then the flask was cooled to $120^{\circ} \mathrm{C}$ and kept for $30 \mathrm{~min}$ before injection of a solution of $10 \mu \mathrm{L}$ TMS in $1 \mathrm{~mL}$ TOP upon vigorous stirring. The growth temperature was $115-120^{\circ} \mathrm{C}$ for $1 \mathrm{~min}$. The ethanolacetone mixture $(1 / 1 \mathrm{v} / \mathrm{v})$ was added to the crude solution followed by centrifugation to precipitate PbS QDs. The precipitate was dissolved in $n$-hexane. The washing steps were repeated three times using $n$-hexane-ethanol as a solvent-nonsolvent pair.

\section{Ligand exchange and preparation of CdSe NPLs-in-polymer and PbS QDs-in-polymer films.}

Ligand exchange to $S^{2-}$ of CdSe NPLs: $2 \mathrm{~mL}$ of the solution of oleate-capped CdSe NPLs in $n$ hexane and $30 \mu \mathrm{L}$ of $48 \%$ solution of $\left(\mathrm{NH}_{4}\right)_{2} \mathrm{~S}$ in water were added to the mixture of $3 \mathrm{~mL}$ MFA and $5 \mathrm{~mL} n$-hexane. After overnight shaking the colored solution of $\mathrm{S}^{2-}$-capped CdSe NPLs in MFA was separated and precipitated in mixture of $1.5 \mathrm{~mL}$ acetone and $4 \mathrm{~mL}$ toluene followed by centrifugation. The precipitate was dissolved in $2 \mathrm{~mL}$ MFA.

Ligand exchange to I- of PbS QDs: The ligand exchange of oleate-capped PbS QDs was carried out in an oxygen-free atmosphere following the recipe developed for surface modification of $\mathrm{PbS}$ QDs with iodide ions. ${ }^{32,42} 300 \mu \mathrm{L}$ of $1 \mathrm{M}$ solution of $\mathrm{NH}_{4} \mathrm{I}$ in MFA were mixed with $2.7 \mathrm{~mL}$ acetone and then added to the diluted solution of the oleate-capped $\mathrm{PbS}$ in $n$-hexane $(6 \mathrm{~mL}, \sim 5-15 \mathrm{mg} / \mathrm{mL})$. After vigorous shaking, the fluffy-like aggregated nanocrystals were centrifuged and separated from the supernatant. An excess of acetone was added to the precipitate to remove the remaining organic molecules and unreacted $\mathrm{NH}_{4} \mathrm{I}$. After centrifugation and drying, the powder was redispersed in $3 \mathrm{~mL}$ 
of MFA. The clear solution was then precipitated with a $n$-hexane/acetone mixture $(1 / 2 \mathrm{v} / \mathrm{v})$. The dried powder was readily dispersible in pure MFA forming stable concentrated solutions.

Ligand modification with $\mathrm{PIB}-\mathrm{NH}_{2}: 0.5 \mathrm{~mL}$ of the resulting concentrated solutions of $\mathrm{S}^{2-}$-capped CdSe NPLs or $\mathrm{I}^{-}$-capped PbS QDs in MFA was added to $0.8 \mathrm{~mL}$ solution of PIB-NH 2 in $n$-octane (10\%-wt.) and $10 \mu \mathrm{L} \mathrm{OlAc.} \mathrm{OlAc} \mathrm{protonates} \mathrm{anchoring} \mathrm{amine} \mathrm{group} \mathrm{of} \mathrm{the} \mathrm{ligand} \mathrm{facilitating} \mathrm{its}$ strong binding to the negatively charged NPLs and QDs. After approx. 30 min of stirring the upper colored layer ( $n$-octane phase) was separated and the NPLs were precipitated by adding a triple excess of acetone relative to $n$-octane followed by centrifugation. The precipitate was dissolved in $0.5 \mathrm{~mL}$ n-octane with the formation of transparent dispersion with concentration exceeding $500 \mathrm{mg} / \mathrm{mL}$. For the preparation of the composite films $20 \mu \mathrm{L}$ of PIB- $\mathrm{NH}_{3}{ }^{+}-\mathrm{S}^{2-}$ - or PIB- $\mathrm{NH}_{3}{ }^{+}-\mathrm{I}^{-}$-capped nanocrystals in $n$-octane were mixed with $80 \mu \mathrm{L}$ of $15 \%$ solution of PIB or PIB-b-PSt. The resulting viscous solution was drop-cast or spin-coated on glass slides with subsequent evaporation of the solvent at room temperature.

Ligand modification with OlAm for preparation of NPLs-in-PLMA composites: In a similar way, $0.5 \mathrm{~mL}$ of the resulting solutions of $\mathrm{S}^{2-}$-capped CdSe NPLs or $\mathrm{I}^{-}$-capped PbS QDs in MFA was added to solution of $20 \mu \mathrm{L}$ OlAm and $5 \mu \mathrm{L}$ OlAc in $0.5 \mathrm{~mL}$ of $n$-hexane. Thus obtained OlAm- ${ }^{2-}$ - or OlAm- $\mathrm{I}^{-}$-capped nanocrystals were purified similar to the $\mathrm{PIB}-\mathrm{NH}_{2}$-functionalized particles and

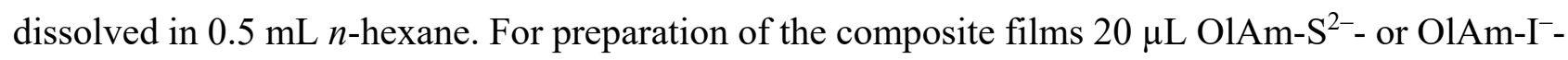
capped nanocrystals in $n$-hexane were mixed with $100 \mu \mathrm{L}$ of $5 \%$-wt. solution of PLMA in toluene. The resulting solution was drop-cast on glass slides with subsequent evaporation of the solvent at room temperature.

\section{Characterization.}

Size exclusion chromatography was performed on an Agilent 1200 apparatus with Nucleogel GPC LM-5, 300/7,7 column and one precolumn (PL gel $5 \mu \mathrm{m}$ guard) thermostated at $30^{\circ} \mathrm{C}$, equipped with a differential refractometer. Solutions of the polymers in tetrahydrofuran (THF) were eluted at a flow rate of $1.0 \mathrm{~mL} / \mathrm{min}$. The calculation of molar mass and polydispersity was based on polystyrene 
standards (Polymer Labs, Germany). ${ }^{1} \mathrm{H} N \mathrm{NM}(400 \mathrm{MHz})$ spectra were recorded in $\mathrm{CDCl}_{3}$ at $25{ }^{\circ} \mathrm{C}$ on a Bruker AC-400 spectrometer calibrated relative to the residual solvent resonance. Absorption spectra of the samples were recorded using a Cary 60 (Varian) spectrophotometer (Varian). $P L$ spectra were acquired on a Fluoromax-4 spectrofluorimeter (Horiba Jobin Yvon, Inc.) by the excitation wavelength set at $400 \mathrm{~nm}$. Absolute $P L$ quantum yields (PLQYs) were determined employing Fluorolog-3 equipped with a Quanta- $\phi$ integrating sphere (Horiba Jobin Yvon, Inc.).

Focused white light irradiation from a powerful $1000 \mathrm{~W}$ xenon lamp was used in photostability tests. The infrared part of the irradiation was cut off by the water filter. Samples were placed in the focus of the light spot. In between illumination cycles, the samples were stored overnight at room temperature. Changes of their optical properties during the illumination were monitored by recording their PL spectra. In the test of chemical stability the QDs-in-polymer films on glass were immersed in a $5 \mathrm{M} \mathrm{HCl}$ aqueous solution. The visual changes of the PL were captured by a photocamera.

\section{RESULTS AND DISCUSSION}

The developed approach to the preparation of stable and transparent semiconductor nanocrystals-in-polymer composites includes three main steps: 1) ligand exchange via solution phase or mild-precipitation techniques on as-synthesized 4 monolayers (MLs) thick CdSe NPLs and PbS QDs from organic capping (myristic and oleic acids) to inorganic $\mathrm{S}^{2-}$ or $\mathrm{I}^{-}$species, respectively, accompanied by the phase transfer of the particles from non-polar solvent to polar MFA; 2) the resulting nanocrystals undergo further ligand shell modification consisting in anchoring $\mathrm{PIB}_{\mathrm{NH}} \mathrm{NH}_{2}$ molecules or their protonated species to sulfide or iodide ions, which transfers the NPLs back to nonpolar solvents, such as $n$-hexane or $n$-octane; 3) PIB-NH2-capped CdSe NPLs are mixed with a solution of either PIB or PIB-b-PSt and the resulting solution is processed via simple drop-casting or spin-coating into thin composite films on glass slides (Figure 1). The first step was introduced in order to improve efficiency of the subsequent capping with $\mathrm{PIB}-\mathrm{NH}_{2}$ ligand, since its affinity to the CdSe surface is not sufficiently strong to replace myristic and oleic acid in the form of firmly bound 
carboxylates. Instead, inorganic ions efficiently replace these ligands creating a base to attach aminofunctionalized short chain PIB molecules. This ligand was specially designed to compatibilize the nanocrystals with PIB-based polymer matrices, which otherwise are poorly miscible and tend to form nontransparent composites due to segregation of the NPLs from the matrix phase resulting in large clusters which scatter visible light. The PIB-NH 2 synthesized in this work via Friedel-Crafts alkylation of 6-phenoxyhexan-1-amine by chlorine-terminated PIB was characterized by $\mathrm{M}_{\mathrm{n}}=1 \times 10^{3}$ and $\mathrm{M}_{\mathrm{w}} / \mathrm{M}_{\mathrm{n}}=1.4$. These ligand molecules possess high binding affinity to the inorganic-capped nanoparticles as well as impressive surface passivation. The hydrocarbon chain of $\mathrm{PIB}-\mathrm{NH}_{2}$ makes the resulting CdSe NPLs and PbS QDs soluble in different non-polar solvents, such as $n$-hexane, $n$ octane, toluene, tetrahydrofuran, chloroform, methylene chloride, etc. Finally, in the third step the NPLs functionalized with this PIB fragment were blended with $15 \%$-wt. solution of PIB with $\mathrm{M}_{\mathrm{n}}=$ $53 \times 10^{3}$ and $\mathrm{M}_{\mathrm{w}} / \mathrm{M}_{\mathrm{n}}=1.4$ or PIB-b-PSt with $\mathrm{M}_{\mathrm{n}}=30 \times 10^{3}$ and $\mathrm{M}_{\mathrm{w}} / \mathrm{M}_{\mathrm{n}}=1.7\left(\mathrm{M}_{\mathrm{n}}\right.$ of PIB-block $=$ $21 \times 10^{3}$ and $\left.\mathrm{M}_{\mathrm{w}} / \mathrm{M}_{\mathrm{n}}=1.2\right)$ in $n$-hexane, $n$-octane, or toluene, followed by subsequent drop-casting or spin-coating onto glass slides. We note that any other solution processing method, such as spin-, spray-coating, inkjet printing, etc., can be used to prepare the composite films.

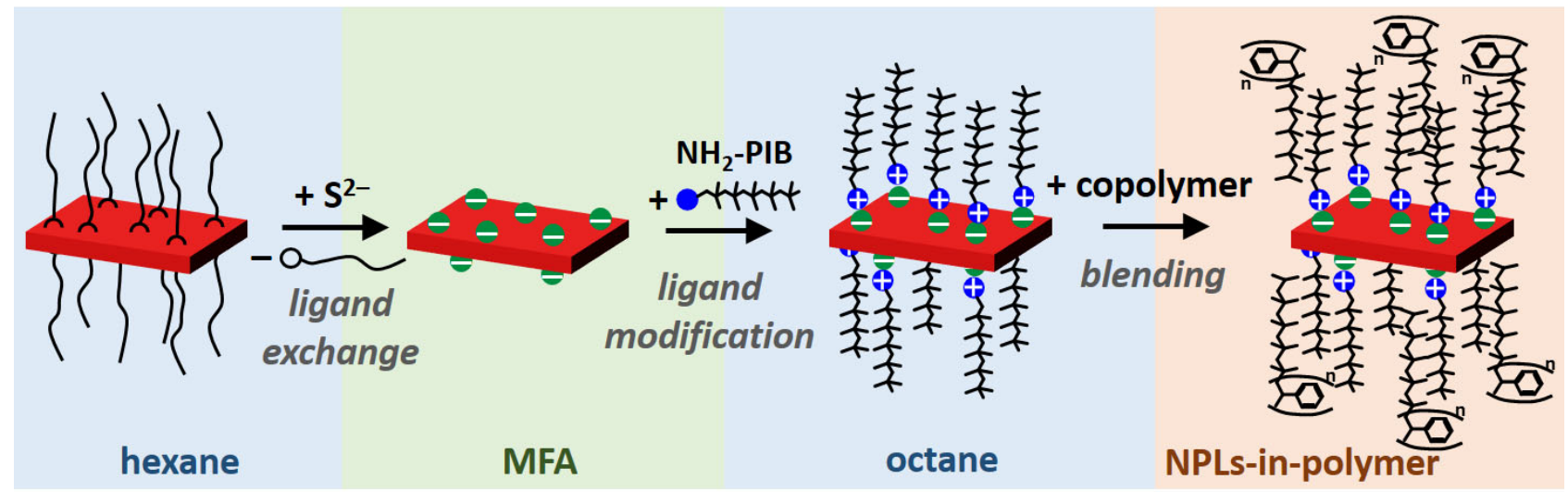

Figure 1. Scheme of the preparation of the CdSe-in-PIB-b-PSt composites including 1) ligand exchange on the as-synthesized NPLs capped with organic ligands for $\mathrm{S}^{2-}$ ions, accompanied by the phase transfer from $n$-hexane to MFA, 2) modification of the ligand shell via attaching $\mathrm{PIB}_{\mathrm{NH}}$ molecules accompanied by the phase transfer from MFA to $n$-octane, and 3) preparation of the composite via blending with PIB-b-PSt in $n$-octane followed by drop-casting a film onto a glass slide. 
As a reference sample in tests of the stability of the prepared NPLs-in-PIB and PIB-b-PSt composites we used NPLs-in-PLMA films. The latter polymer is quite common matrix for encapsulation of semiconductor nanocrystals owing to its dodecyl hydrocarbon tales, which can well accommodate as-synthesized particles bearing similar hydrocarbon-containing moieties on the surface forming transparent composites. All three composites were brightly fluorescent transparent films, as shown in Figure 2a. As we recently demonstrated, ${ }^{43}$ the PL of 4 ML thick CdSe NPLs drastically changes upon capping with $\mathrm{S}^{2-}$, namely initially green emission color transforms to red accompanied by a large shift of the PL maximum from $512 \mathrm{~nm}$ to $630 \mathrm{~nm}$ and broadening of the full width at a half maximum (FWHM) from $9 \mathrm{~nm}$ to $30 \mathrm{~nm}$ (Figure 2c). This clearly indicates that the surface of the NPLs is very sensitive to the alteration of the surrounding environment, making them a perfect object to study stability of the corresponding composites with polymers. In order to correctly compare the properties of three different composites, we incorporated $\mathrm{S}^{2-}$-capped CdSe NPLs into PLMA, instead of employing directly as-synthesized NPLs, which also are compatible with this polymer. In this way, $\mathrm{S}^{2-}$-capped CdSe NPLs were transferred from MFA solution back to nonpolar organics by adding OlAm, that ensures similar NPL surface chemistry in all three types of samples. We note that to make the interaction between amines and sulfur ions on the NPL surface more efficient small amounts of OlAc were added in the second step. This resulted in partial protonation of amino-groups forming $-\mathrm{NH}_{3}{ }^{+}-\mathrm{S}^{2-}-\mathrm{CdSe}$ bonds. The OlAm- $\mathrm{S}^{2-}-\mathrm{CdSe}$ were finally blended with high-molecular PLMA $\left(\mathrm{M}_{\mathrm{n}}=57 \times 10^{4}, \mathrm{M}_{\mathrm{w}} / \mathrm{M}_{\mathrm{n}}=2.4\right)$ similar to the composites with PIB and PIB-bPSt. As seen from the absorption and PL spectra of the composites, all three exhibit almost identical spectral shapes and peak positions (Figure 2b,c). 

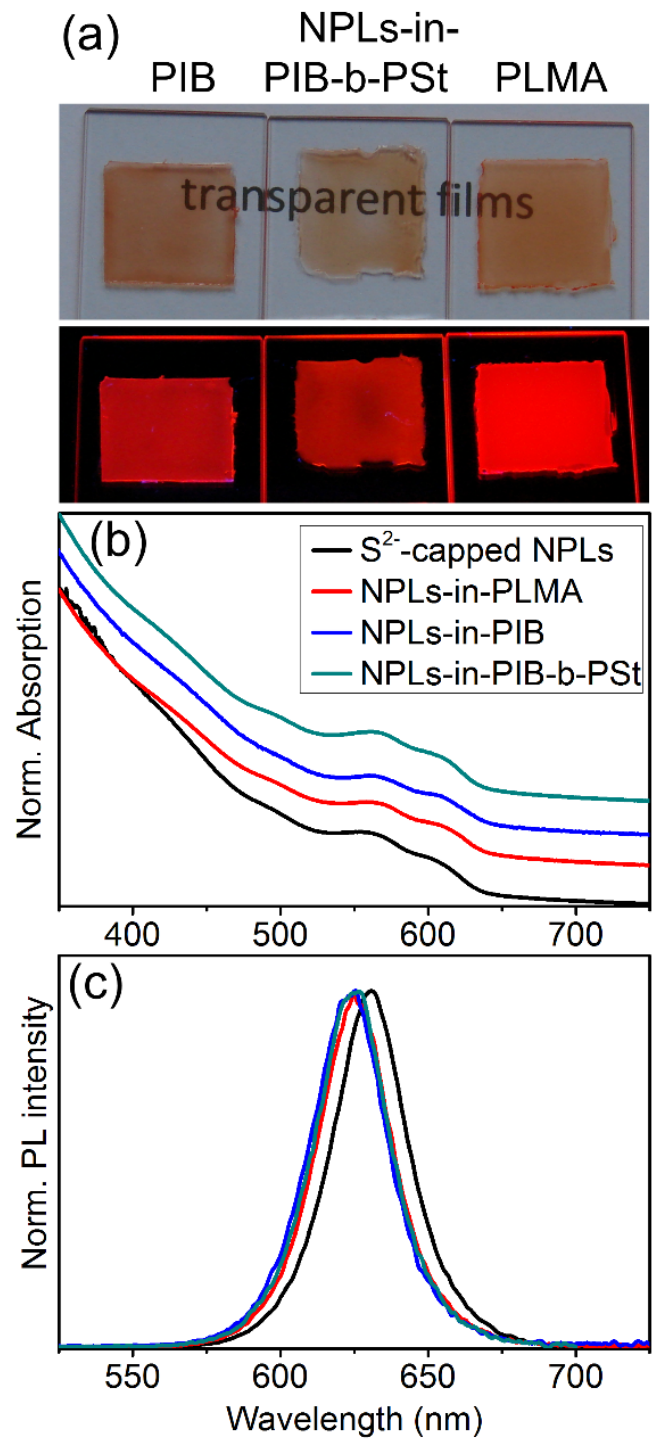

Figure 2. (a) Photos of CdSe NPLs-in-polymer composites: NPLs-in-PIB, NPLs-in-PIB-b-PSt, and NPLs-in-PLMA under day (top) and UV-light (bottom). Absorption (b) and PL (c) spectra of the corresponding composites compared with those of $\mathrm{S}^{2-}$-capped CdSe NPLs. Absorption spectra are vertically shifted for clarity.

To assess the stability of the obtained composites, we first applied photodegradation test already exploited in our previous work. ${ }^{12,18}$ In this experiment, films of NPLs-in-polymer cast on glass were illuminated by a powerful $1000 \mathrm{~W}$ white light xenon lamp with the beam focused into a spot of approx. $1 \mathrm{~cm}$ in diameter. Changes during the treatment were monitored by optical spectroscopy, in particular by PL measurements, as the PL is very sensitive to the state of the surface of QDs. For example, defects created on the surface by oxidation or any degradation process in general will be 
immediately reflected in quenching of the emission. Figure 3 displays changes of the integrated PL spectra of all three composite samples together with a control film made of solely $\mathrm{S}^{2-}$-capped CdSe NPLs without a polymer matrix. The latter exhibited a surprisingly good stability over 500 min of the irradiation maintaining its average PL at the level of $80 \%$ of the initial value. By this, at the very beginning of the exposure the fluorescence intensity raised by approx. $50 \%$ indicating photobrightening of the particles most probably due to the removal of defects on the surface. The least photostable composite was NPLs-in-PLMA whose PL intensity dropped by approx. 35\% during first $10 \mathrm{~min}$ of the treatment and remained at $44 \%$ on average of the initial value over approx. 700 min of the irradiation. Distinctly different behavior was observed by testing NPLs-in-PIB and -PIBb-PSt composites. After initial drop of the intensity, the PL restored to its initial value during 20-30 min and continued increasing in both cases reaching its maximum after 5 hours for the NPLs-in-PIBb-PSt film and 6.5 hours for NPLs-in-PIB film, amounted to 5.2-fold and 2.4-fold enhancement, respectively, compared to the initial values. A similar light soaking effect we observed recently testing CuInS2-based QDs incorporated into polystyrene matrix. ${ }^{12}$ Lower stability of NPLs-in-PLMA composite against irradiation can be explained by a well-known ability of the polyacrylates to depolymerize favored by the formation of quite stable macroradicals, which in turn can damage the surface of the NPLs forming trap states. ${ }^{44-45}$

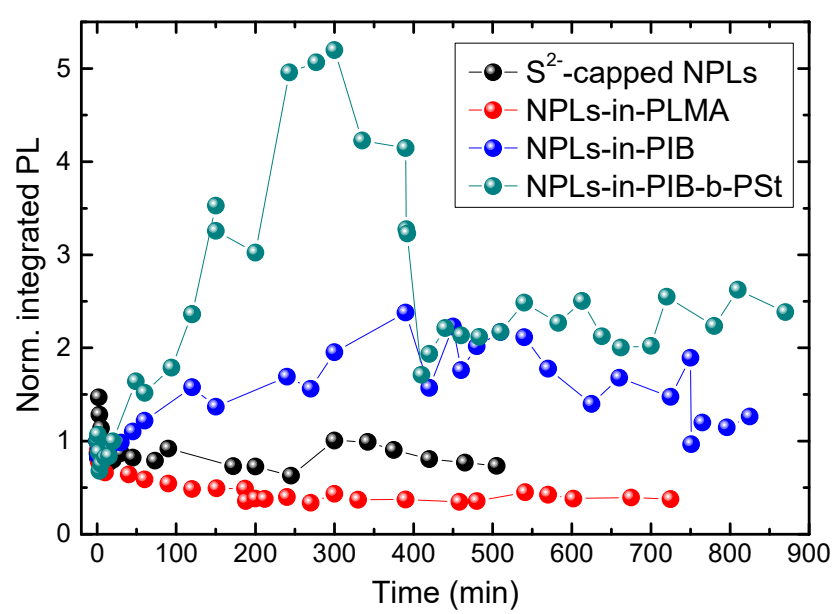

Figure 3. Normalized integrated PL signal of films-on-glass made of $\mathrm{S}^{2-}$-capped CdSe NPLs, as well as NPLs-in-PIB, PIB-b-PSt, and -PLMA composites versus time of the illumination by $1000 \mathrm{~W}$ xenon lamp. 
Despite the advantages of the PIB matrix as an encapsulant for semiconductor nanocrystals, the pure polymer is an elastomer, that is soft at ambient conditions (its glass transition temperature is approx. $-74^{\circ} \mathrm{C}$ for low-molecular weights and approx. $-70^{\circ} \mathrm{C}$ for high-molecular weights $)^{35}$. Although such soft elastic polymers as pure PIB or PLMA $\left(\mathrm{T}_{\mathrm{g}}=-50{ }^{\circ} \mathrm{C}\right)^{46}$ are not optimal for fabricating photochemically and thermally stable composite materials, they can be blended with or reinforced by placing a layer of a more thermostable polymer on top of the composite film. As an alternative we propose PIB-b-PSt block-copolymer, polystyrene blocks of which impart rigidity to the matrix, while PIB ensures low gas permeability and overall chemical inertness. Indeed, as follows from the results of the photostability tests, this specially designed polymer provided the best protection to the NPLs in terms of preservation and even remarkable enhancement of their PL intensity. Absorption spectra of all tested samples indicate similar changes, namely a pronounced blue shift of the heavy hole and the light hole transitions accompanied by smoothing both features (Figure SI2).

Furthermore, we used this copolymer to encapsulate spherical PbS nanocrystals, which are prone to oxidation and thus are very sensitive to the presence of air $^{32-33}$. $\mathrm{I}^{-}$-capped $\mathrm{PbS}$ QDs were processed into QDs-in- PIB-b-PSt and -PLMA composites analogous to CdSe NPLs (Figure 1). The spectra of the integrated PIB-NH${ }_{3}^{+}-\mathrm{I}^{-}$-capped PbS QDs in PIB-b-PSt matrix resemble those of PIB$\mathrm{NH}_{3}{ }^{+}-\mathrm{I}^{-}$-capped $\mathrm{PbS}$ QDs in solution, whereas the ligand exchange from oleate to iodide led to a remarkable red shift of the both spectra followed by a further, less pronounced red shift upon capping with PIB-NH2 (Figure SI3a,b). Results of the photostability tests are displayed in Figure SI3c. As in the case of CdSe NPLs, the copolymer matrix provided significantly better protection to PbS QDs than PLMA. Thus, half-life (the drop of the PL spectrum area by $50 \%$ compared to the initial value) of their PL in PLMA was evaluated as 3 min, whereas in PIB-b-PSt emission lasted remarkably longer with half-life of approx. $45 \mathrm{~min}$.

In addition to the photostability test, we performed qualitative investigation of the chemical stability of the obtained composites in highly concentrated hydrochloric acid solution. The films on 
glass were basically immersed in the $5 \mathrm{M}$ acid solution, the visual changes of the PL were captured by a photocamera. As seen in Figure 4, the fluorescence intensity of the NPLs in PLMA matrix dropped significantly already after 2 hours of soaking, and after 4 hours the PL was hardly visible indicating either complete decomposition of the plates or formation of a large number of defects on their surface. Unlike, NPLs-in-PLMA, both NPLs-in-PIB and -PIB-b-PSt proved to be much more stable in such aggressive environment still retaining their PL even after 4 days of soaking in $\mathrm{HCl}$ solution. This underlines excellent stability of the new composites not only against irradiation by a powerful light source, but also against strongly corrosive chemical substances, which is particularly beneficial for outdoor application of these materials, e.g. as luminescent solar concentrators.

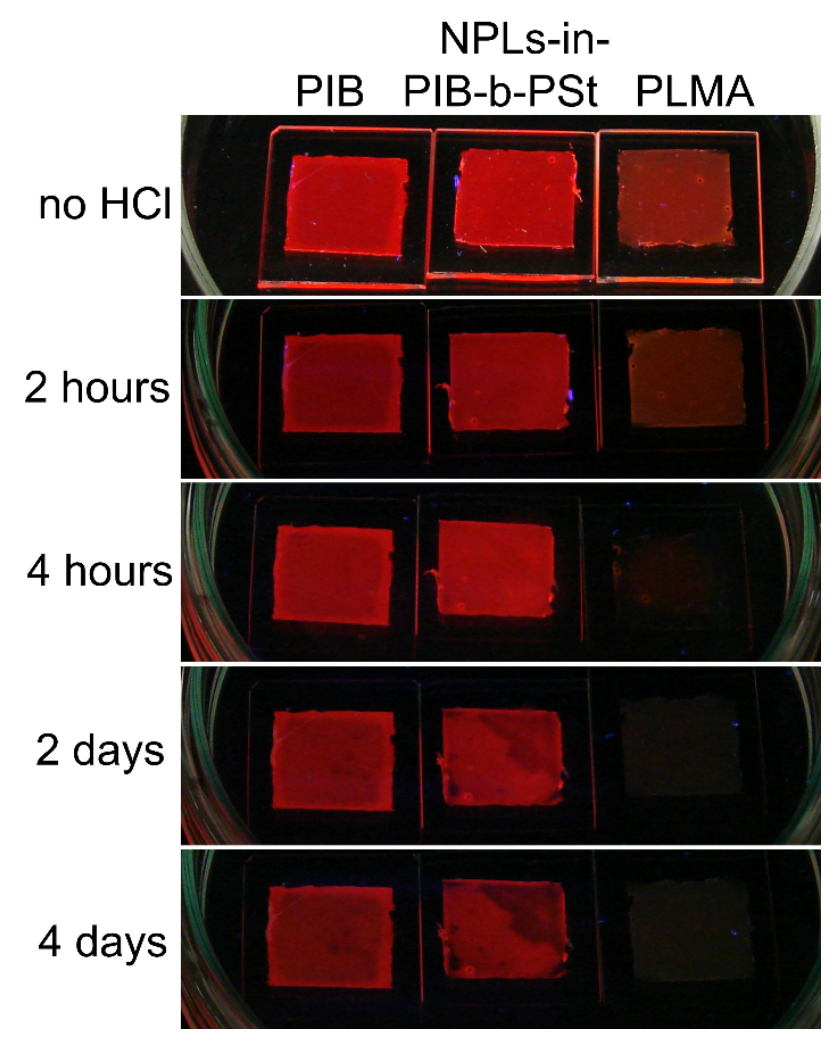

Figure 4. Photographs of CdSe NPLs-in-PIB, -PIB-b-PSt, and -PLMA films deposited on glass slides before and 2 hours, 4 hours, 2 days, and 4 days after adding $5 \mathrm{M} \mathrm{HCl}$, under $\mathrm{UV}$-light.

\section{CONCLUSIONS}

We introduced new polymer matrices made of isobutylene and its block copolymer with styrene for encapsulation of colloidal semiconductor nanocrystals. The nanoparticles under study were CdSe 
NPLs and PbS QDs, both known for their sensitive optical properties, in particular fluorescence. In order to compatibilize the nanocrystals with the matrices we designed a short-chain PIB functionalized with amino-group as a ligand. This ligand was applied to $\mathrm{S}^{2-}$-capped CdSe NPLs and $\mathrm{I}^{-}$-capped PbS QDs resulting in solubilization of the particles in organic solvents. The stability of the nanoparticles-in-PIB and -in-PIB-b-PSt composites were benchmarked against that of NPLs(QDs)in-PLMA. The nanoparticle-in-polymer composites were prepared simple by drop-casting mixed solutions onto glass slides. Our results of the photostability and chemical stability tests clearly demonstrate that nanocrystals in polyisobutylene-based matrices are much more stable against photoand chemical degradation. Furthermore, we observed a significant increase in fluorescence intensity over irradiation time attributed to the light soaking effect, which is highly beneficial for practical application of the obtained materials. We believe that the isobutylene-based polymers introduced in this work can serve as gas-tight matrices for many other semiconductor nanoparticles. The developed composites are of particular interest for application in optoelectronic devices, such as colorconversion LEDs, laser diodes, luminescent solar concentrators, etc.

\section{Acknowledgements}

D. S. acknowledges the support by the German Academic Exchange Service (DAAD) under the grant agreement Funding programme/-ID: Bilateral Exchange of Academics 2016 (57210233) and ERASMUS+ Programme. The authors are grateful to D. Astashko (Belarusian State University) for the synthesis of 6-phenoxyhexan-1-amine. This work was supported by the EU Horizon 2020 project MiLEDi (779373).

Supporting Information: list of chemicals, additional experimental methods, additional absorption and PL spectra of CdSe NPLs as well as PbS QDs.

\section{References}


1. Talapin, D. V.; Lee, J.-S.; Kovalenko, M. V.; Shevchenko, E. V., Prospects of Colloidal Nanocrystals for Electronic and Optoelectronic Applications. Chem. Rev. 2010, 110, 389-458.

2. Kovalenko, M. V.; Manna, L.; Cabot, A.; Hens, Z.; Talapin, D. V.; Kagan, C. R.; Klimov, V. I.; Rogach, A. L.; Reiss, P.; Milliron, D. J.; Guyot-Sionnnest, P.; Konstantatos, G.; Parak, W. J.; Hyeon, T.; Korgel, B. A.; Murray, C. B.; Heiss, W., Prospects of Nanoscience with Nanocrystals. ACS Nano 2015, 9, 1012-1057.

3. Shirasaki, Y.; Supran, G. J.; Bawendi, M. G.; Bulović, V., Emergence of Colloidal QuantumDot Light-Emitting Technologies. Nat. Photonics 2013, 7, 13-23.

4. Demir, H. V.; Nizamoglu, S.; Erdem, T.; Mutlugun, E.; Gaponik, N.; Eychmüller, A., Quantum Dot Integrated LEDs Using Photonic and Excitonic Color Conversion. Nano Today 2011, $6,632-647$.

5. Carey, G. H.; Abdelhady, A. L.; Ning, Z.; Thon, S. M.; Bakr, O. M.; Sargent, E. H., Colloidal Quantum Dot Solar Cells. Chem. Rev. 2015, 115, 12732-12763.

6. Kramer, I. J.; Sargent, E. H., The Architecture of Colloidal Quantum Dot Solar Cells: Materials to Devices. Chem. Rev. 2013, 114, 863-882.

7. Pietryga, J. M.; Park, Y.-S.; Lim, J.; Fidler, A. F.; Bae, W. K.; Brovelli, S.; Klimov, V. I., Spectroscopic and Device Aspects of Nanocrystal Quantum Dots. Chem. Rev. 2016, 116, 1051310622.

8. Zhou, Y.; Zhao, H.; Ma, D.; Rosei, F., Harnessing the Properties of Colloidal Quantum Dots in Luminescent Solar Concentrators. Chem. Soc. Rev. 2018, 47, 5866-5890.

9. Sapsford, K. E.; Algar, W. R.; Berti, L.; Gemmill, K. B.; Casey, B. J.; Oh, E.; Stewart, M. H.; Medintz, I. L., Functionalizing Nanoparticles with Biological Molecules: Developing Chemistries That Facilitate Nanotechnology. Chem. Rev. 2013, 113, 1904-2074.

10. Medintz, I. L.; Uyeda, H. T.; Goldman, E. R.; Mattoussi, H., Quantum Dot Bioconjugates for Imaging, Labelling and Sensing. Nat. Mater. 2005, 4, 435-446. 
11. Sperling, R. A.; Parak, W. J., Surface Modification, Functionalization and Bioconjugation of Colloidal Inorganic Nanoparticles. Phil. Trans. R. Soc. A 2010, 368, 1333-1383.

12. Lesyuk, R.; Cai, B.; Reuter, U.; Gaponik, N.; Popovych, D.; Lesnyak, V., Quantum-Dot-inPolymer Composites via Advanced Surface Engineering. Small Methods 2017, 1, 1700189.

13. Lee, J.; Sundar, V. C.; Heine, J. R.; Bawendi, M. G.; Jensen, K. F., Full Color Emission from II-VI Semiconductor Quantum Dot-Polymer Composites. Adv. Mater. 2000, 12, 1102-1105.

14. Zhang, H.; Cui, Z.; Wang, Y.; Zhang, K.; Ji, X.; Lu, C.; Yang, B.; Gao, M., From WaterSoluble CdTe Nanocrystals to Fluorescent Nanocrystal-Polymer Transparent Composites Using Polymerizable Surfactants. Adv. Mater. 2003, 15, 777-780.

15. Pietra, F.; van Dijk - Moes, R. J. A.; Ke, X.; Bals, S.; Van Tendeloo, G.; de Mello Donega, C.; Vanmaekelbergh, D., Synthesis of Highly Luminescent Silica-Coated CdSe/CdS Nanorods. Chem. Mater. 2013, 25, 3427-3434.

16. Yang, Y.; Jing, L.; Yu, X.; Yan, D.; Gao, M., Coating Aqueous Quantum Dots with Silica via Reverse Microemulsion Method: Toward Size-Controllable and Robust Fluorescent Nanoparticles. Chem. Mater. 2007, 19, 4123-4128.

17. Lox, J. F. L.; Eichler, F.; Erdem, T.; Adam, M.; Gaponik, N.; Demir, H. V.; Lesnyak, V.; Eychmüller, A., Brightly Luminescent Cu-Zn-In-S/ZnS Core/Shell Quantum Dots in Salt Matrices. Z. Phys. Chem. 2018, DOI: 10.1515/zpch-2017-1086.

18. Otto, T.; Müller, M.; Mundra, P.; Lesnyak, V.; Demir, H. V.; Gaponik, N.; Eychmüller, A., Colloidal Nanocrystals Embedded in Macrocrystals: Robustness, Photostability, and Color Purity. Nano Lett. 2012, 12, 5348-5354.

19. Benad, A.; Guhrenz, C.; Bauer, C.; Eichler, F.; Adam, M.; Ziegler, C.; Gaponik, N.; Eychmüller, A., Cold Flow as Versatile Approach for Stable and Highly Luminescent Quantum DotSalt Composites. ACS Appl. Mater. Interfaces 2016, 8, 21570-21575. 
20. Adam, M.; Gaponik, N.; Eychmüller, A.; Erdem, T.; Soran-Erdem, Z.; Demir, H. V., Colloidal Nanocrystals Embedded in Macrocrystals: Methods and Applications. J. Phys. Chem. Lett. 2016, 7, 4117-4123.

21. Adam, M.; Wang, Z.; Dubavik, A.; Stachowski, G. M.; Meerbach, C.; Soran-Erdem, Z.; Rengers, C.; Demir, H. V.; Gaponik, N.; Eychmüller, A., Liquid-Liquid Diffusion-Assisted Crystallization: A Fast and Versatile Approach toward High Quality Mixed Quantum Dot-Salt Crystals. Adv. Funct. Mater. 2015, 25, 2638-2645.

22. Frolova, E.; Otto, T.; Gaponik, N.; Lesnyak, V., Incorporation of CdTe Nanocrystals into Metal Oxide Matrices Towards Inorganic Nanocomposite Materials. Z. Phys. Chem. 2018, 232, $1335-1352$.

23. Meinardi, F.; Colombo, A.; Velizhanin, K. A.; Simonutti, R.; Lorenzon, M.; Beverina, L.; Viswanatha, R.; Klimov, V. I.; Brovelli, S., Large-Area Luminescent Solar Concentrators Based on 'Stokes-Shift-Engineered' Nanocrystals in a Mass-Polymerized PMMA Matrix. Nat. Photon. 2014, 8, 392-399.

24. Coropceanu, I.; Bawendi, M. G., Core/Shell Quantum Dot Based Luminescent Solar Concentrators with Reduced Reabsorption and Enhanced Efficiency. Nano Lett. 2014, 14, 4097-4101. 25. Pinaud, F.; King, D.; Moore, H.-P.; Weiss, S., Bioactivation and Cell Targeting of Semiconductor CdSe/ZnS Nanocrystals with Phytochelatin-Related Peptides. J. Am. Chem. Soc. 2004, 126, 6115-6123.

26. Wang, M.; Dykstra, T. E.; Lou, X.; Salvador, M. R.; Scholes, G. D.; Winnik, M. A., Colloidal CdSe Nanocrystals Passivated by a Dye-Labeled Multidentate Polymer: Quantitative Analysis by Size-Exclusion Chromatography. Angew. Chem. Int. Ed. 2006, 45, 2221-2224.

27. Guo, W.; Li, J. J.; Wang, Y. A.; Peng, X., Luminescent CdSe/CdS Core/Shell Nanocrystals in Dendron Boxes: Superior Chemical, Photochemical and Thermal Stability. J. Am. Chem. Soc. 2003, 125, 3901-3909. 
28. Farmer, S. C.; Patten, T. E., Photoluminescent Polymer/Quantum Dot Composite Nanoparticles. Chem. Mater. 2001, 13, 3920-3926.

29. Sayevich, V.; Guhrenz, C.; Dzhagan, V. M.; Sin, M.; Werheid, M.; Cai, B.; Borchardt, L.; Widmer, J.; Zahn, D. R. T.; Brunner, E.; Lesnyak, V.; Gaponik, N.; Eychmüller, A., Hybrid NButylamine-Based Ligands for Switching the Colloidal Solubility and Regimentation of InorganicCapped Nanocrystals. ACS Nano 2017, 11, 1559-1571.

30. Sau, T. K.; Murphy, C. J., Self-Assembly Patterns Formed upon Solvent Evaporation of Aqueous Cetyltrimethylammonium Bromide-Coated Gold Nanoparticles of Various Shapes. Langmuir 2005, 21, 2923-2929.

31. Guhrenz, C.; Sayevich, V.; Weigert, F.; Hollinger, E.; Reichhelm, A.; Resch-Genger, U.; Gaponik, N.; Eychmüller, A., Transfer of Inorganic-Capped Nanocrystals into Aqueous Media. $J$. Phys. Chem. Lett. 2017, 8, 5573-5578.

32. Sayevich, V.; Gaponik, N.; Plötner, M.; Kruszynska, M.; Gemming, T.; Dzhagan, V. M.; Akhavan, S.; Zahn, D. R. T.; Demir, H. V.; Eychmüller, A., Stable Dispersion of Iodide-Capped PbSe Quantum Dots for High-Performance Low-Temperature Processed Electronics and Optoelectronics. Chem. Mater. 2015, 27, 4328-4337.

33. Sykora, M.; Koposov, A. Y.; McGuire, J. A.; Schulze, R. K.; Tretiak, O.; Pietryga, J. M.; Klimov, V. I., Effect of Air Exposure on Surface Properties, Electronic Structure, and Carrier Relaxation in PbSe Nanocrystals. ACS Nano 2010, 4, 2021-2034.

34. Kunal, K.; Paluch, M.; Roland, C. M.; Puskas, J. E.; Chen, Y.; Sokolov, A. P., Polyisobutylene: A Most Unusual Polymer. J. Polym. Sci. B 2008, 46, 1390-1399.

35. Kostjuk, S. V.; Yeong, H. Y.; Voit, B., Cationic Polymerization of Isobutylene at Room Temperature. J. Polym. Science, Part A: Polym. Chem. 2013, 51, 471-486.

36. Banerjee, S.; Tripathy, R.; Cozzens, D.; Nagy, T.; Keki, S.; Zsuga, M.; Faust, R., Photoinduced Smart, Self-Healing Polymer Sealant for Photovoltaics. ACS Appl. Mater. Interfaces 2015, 7, 2064-2072. 
37. Bag, M.; Banerjee, S.; Faust, R.; Venkataraman, D., Self-Healing Polymer Sealant for Encapsulating Flexible Solar Cells. Sol. Energ. Mat. Sol. Cells 2016, 145, Part 3, 418-422.

38. Shiman, D. I.; Vasilenko, I. V.; Kostjuk, S. V., Cationic Polymerization of Isobutylene by $\mathrm{AlCl}_{3} /$ Ether Complexes in Non-Polar Solvents: Effect of Ether Structure on the Selectivity of B-H Elimination. Polymer 2013, 54, 2235-2242.

39. Morgan, D. L.; Martinez-Castro, N.; Storey, R. F., End-Quenching of TiCl4-Catalyzed Quasiliving Polyisobutylene with Alkoxybenzenes for Direct Chain End Functionalization. Macromolecules 2010, 43, 8724-8740.

40. Storey, R. F.; Chisholm, B. J., Aspects of the Synthesis of Poly(Styrene-b-Isobutylene-bStyrene) Block Copolymers Using Living Carbocationic Polymerization. Macromolecules 1993, 26, 6727-6733.

41. Hines, M. A.; Scholes, G. D., Colloidal PbS Nanocrystals with Size-Tunable near-Infrared Emission: Observation of Post-Synthesis Self-Narrowing of the Particle Size Distribution. Adv. Mater. 2003, 15, 1844-1849.

42. Sayevich, V.; Cai, B.; Benad, A.; Haubold, D.; Sonntag, L.; Gaponik, N.; Lesnyak, V.; Eychmüller, A., 3D Assembly of All-Inorganic Colloidal Nanocrystals into Gels and Aerogels. Angew. Chem. Int. Ed. 2016, 55, 6334-6338.

43. the manuscript is currently under revision in Adv. Optic. Mater.

44. MacCallum, J. R.; Schoff, C. K., Photolytic Decomposition of Polymethacrylates. Part. 1.Poly(Methyl Methacrylate); Kinetics of Decomposition. Trans. Faraday Soc. 1971, 67, 2372-2382. 45. Mita, I.; Obata, K.; Horie, K., Photoinitiated Thermal Degradation of Polymers II. Poly(Methyl Methacrylate). Polym. J. 1990, 22, 397-410.

46. Floudas, G.; Placke, P.; Stepanek, P.; Brown, W.; Fytas, G.; Ngai, K. L., Dynamics of the "Strong" Polymer of N-Lauryl Methacrylate Below and above the Glass Transition. Macromolecules 1995, 28, 6799-6807. 


\section{ToC Figure}

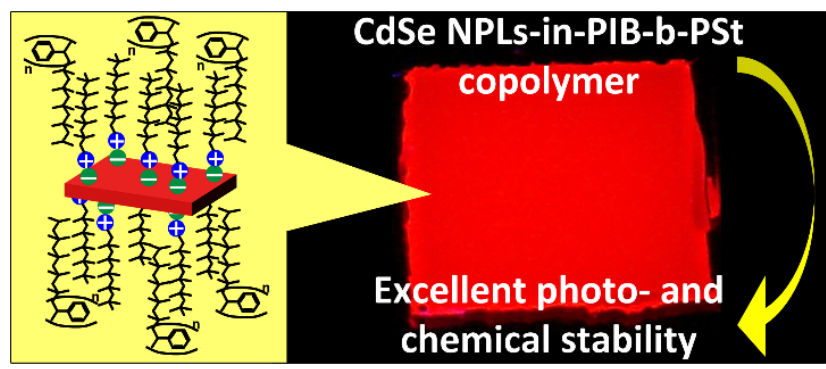

